\title{
An improved solvent-free synthesis of flunixin and 2-(arylamino) nicotinic acid derivatives using boric acid as catalyst
}

\author{
Mahsa Yarhosseini, Shahrzad Javanshir ${ }^{*}$ (I), Zahra Dolatkhah and Mohammad G. Dekamin
}

\begin{abstract}
A simple solvent-free protocol for the preparation of flunixin, a potent non-narcotic, non-steroidal anti-inflammatory drugs is reported using boric acid as catalyst. Its salt, flunixin meglumine are then prepared under reflux in EtOH. This sustainable method are then extended for the synthesis of a series of 2-(arylamino) nicotinic acid derivatives. The present protocol combines non-hazardous neat conditions with associated benefits like excellent yield, straightforward workup, and use of readily available and safe catalyst in the absence of any solvent, which are important factors in the pharmaceutical industry. The pathway for catalytic activation of 2-chloronicotic acid with boric acid was also investigated using Gaussian 03 program package.
\end{abstract}

Keywords: Homogeneous catalysis, Solvent-free, Non-steroidal anti-inflammatory drugs (NSAID), N-Methyl-oglucamine, Boric acid, Anilino-nicotinic acid

\section{Introduction}

Flunixin, 2-(2-methyl-3-trifluoromethylanilino)nicotinic acid (Fig. 1) is a non-narcotic, non-steroidal anti-inflammatory drug (NSAID) and cyclooxygenase inhibitor with potent antipyretic and analgesic activity, parenterally administered in clinical and veterinary applications [13]. It is frequently administered in the form of the meglumine salt.

The analgesic activity of $N$-methyl-D-glucamine salt of flunixin (flunixin meglumine) is comparable to that observed by powerful narcotic analgesics such as morphine, meperidine hydrochloride, and pentazocine. However, the undesirable side effects are less compared to the above mentioned narcotics analgesics and drug dependence liability does not occur [4]. Apart from its parenteral analgesic activities, flunixin meglumine also possesses anti-inflammatory attributes [5-8]. Flunixin meglumine was first reported in 1975 [9] and is the active pharmaceutical ingredient in numerous drug products such as

\footnotetext{
*Correspondence: shjavan@iust.ac.ir

Heterocyclic Chemistry Research Laboratory, Department of Chemistry, Iran University of Science and Technology, Tehran 16846-13114, Iran
}

Resflor, Banamine Solution, Banamine Paste, Banamine Granules and Finadyne [10-19].

So far, several improved methods have been developed for the synthesis of flunixin including classical reflux in water [12], xylene [5] and ethylene glycol [20]. Some of these methods suffer from several drawbacks such as difficult workup, long reaction times, use of large quantities of non-green organic solvents such as xylene that are harmful for environment and harsh reaction conditions. In this regard, solvent-free approach which has become increasingly popular in recent years for reasons of economy and pollution prevention, as well as cleaner products, simple work-up, high-speed due to the high concentration of materials, and excellent yields would be the ideal approach, as it is often claimed that "the best solvent is no solvent" [21]. To the best of our knowledge, we herein report the first green synthesis of 2-(2-methyl-3-trifluoromethylanilino)nicotinic acid (3a) under solvent-free conditions in the presence of catalytic amount of Boric acid. In this contribution, studies to reach a broader scope and generality of this reaction is also presented using other anilines, as nucleophiles, some 2 -arylaminonicotinic acids derivatives 3 were also synthesized by this method. 
<smiles>Cc1c(Nc2ncccc2C(=O)O)cccc1C(F)(F)F</smiles>

Fig. 1 Chemical structure of flunixin

\section{Results and discussion}

Boric acid $\left[\mathrm{H}_{3} \mathrm{BO}_{3}\right.$ or $\left.\mathrm{B}(\mathrm{OH})_{3}\right]$ has attracted particular attention in recent years as catalyst in organic synthesis [22-25], because of many advantages such as uncomplicated handling, inexpensiveness, eco-friendly nature and commercially available [26]. Consequently, we have considered the synthesis of 2-(2-methyl-3-trifluoromethylanilino)nicotinic acid (3a), in the presence of boric acid under solvent-free conditions, and its salt, flunixin meglumine (6) under reflux in EtOH (Scheme 1).

In a first attempt, the reaction of 2-methyl-3-trifluoromethylanilin (1) with 2-chloronicotinic acid (2) was examined under various reaction conditions, the results and the optimization of reaction conditions are summarized in Table 1. Initially, the effect of acid and basic catalysts was tested. In the absence of any catalyst no reaction took place under reflux in water (Table 1, entry 1), and also under solvent-free condition the desired product was obtained in low yield in the absence of any catalyst (entry 2). When this reaction is carried out in the presence of a catalyst such as $\mathrm{K}_{2} \mathrm{CO}_{3}, \mathrm{NEt}_{3}, \mathrm{Fe}_{3} \mathrm{O}_{4}$, and $\mathrm{DABCO}$ in the presence and absence of solvent only a trace amount of product was detected even after $24 \mathrm{~h}$ (entries 5-8), while the desired product was obtained in moderate yield in the presence of PTSA and boric acid (entries 9 and 10). Considering the cost and toxicity of these two catalysts, and also due to a slight difference in efficiency between them (entries 21 and 23), we choose boric acid as optimal catalyst.

In the next step the effect of various solvents and temperature $\left(80-150{ }^{\circ} \mathrm{C}\right.$ ) was examined (Table 1, entries $8-22$ ). The best yield was obtained at $120^{\circ} \mathrm{C}$ under solvent-free condition (entry 17). Therefore, considering the viewpoints of green chemistry, the synthesis of flunixin was carried out under solvent-free condition. And finally, we studied the effect of the ratio of reactants on the yield of the reaction. When the reagents were used in an<smiles>Cc1c(N)cccc1C(F)(F)F</smiles>

1

$\underset{\text { Solvent free }}{\stackrel{\text { Boric acid }}{\longrightarrow}}$<smiles>O=C(O)c1cccnc1Cl</smiles>

2<smiles>Cc1c(Nc2ncccc2C(=O)O)cccc1C(F)(F)F</smiles>

$3 a$<smiles>CNCC(O)C(O)C(O)C(O)CO</smiles>

5

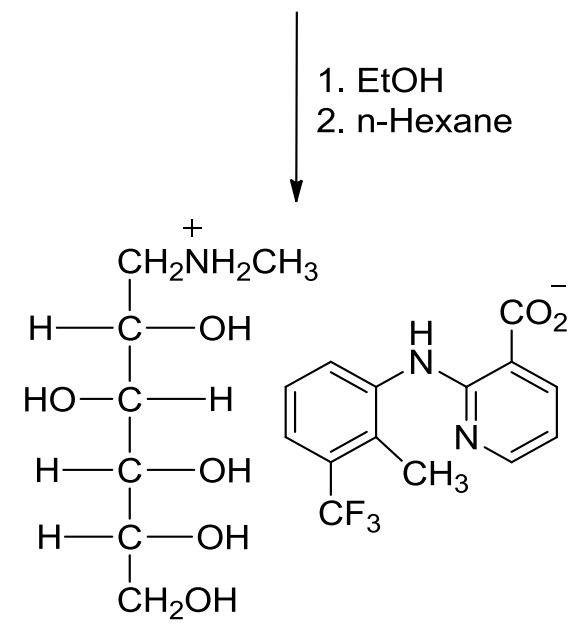

6

Scheme 1 Synthesis of flunixin meglumine 
Table 1 Optimization of the reaction conditions for the synthesis of ( $3 a$ )

\begin{tabular}{|c|c|c|c|c|c|c|c|}
\hline Entry & Ratio of $1 / 2$ & Catalyst & Catalyst loading (mole \%) & Solvent & $\operatorname{Temp}\left({ }^{\circ} \mathrm{C}\right)$ & Time (h) & Yield $^{c}(\%)$ \\
\hline 1 & $2: 1$ & - & - & $\mathrm{H}_{2} \mathrm{O}$ & Reflux & 24 & - \\
\hline 2 & $2: 1$ & - & - & - & 100 & 10 & 35 \\
\hline 3 & $2: 1$ & $\mathrm{~K}_{2} \mathrm{CO}_{3}$ & 15 & - & 100 & 24 & Trace \\
\hline 4 & $2: 1$ & $\mathrm{NEt}_{3}$ & 15 & - & 100 & 24 & - \\
\hline 5 & $2: 1$ & $\mathrm{~K}_{2} \mathrm{CO}_{3}$ & 15 & $\mathrm{H}_{2} \mathrm{O}$ & Reflux & 24 & Trace \\
\hline 6 & $2: 1$ & $\mathrm{NEt}_{3}$ & 15 & $\mathrm{H}_{2} \mathrm{O}$ & Reflux & 24 & - \\
\hline 7 & $2: 1$ & $\mathrm{Fe}_{3} \mathrm{O}_{4}$ & 15 & $\mathrm{H}_{2} \mathrm{O}$ & Reflux & 24 & - \\
\hline 8 & $2: 1$ & $\mathrm{DABCO}^{\mathrm{a}}$ & 15 & $\mathrm{H}_{2} \mathrm{O}$ & Reflux & 24 & Trace \\
\hline 9 & $2: 1$ & PTSA & 15 & $\mathrm{H}_{2} \mathrm{O}$ & Reflux & 24 & 65 \\
\hline 10 & $2: 1$ & $\mathrm{H}_{3} \mathrm{BO}_{3}$ & 15 & $\mathrm{H}_{2} \mathrm{O}$ & Reflux & 24 & 60 \\
\hline 11 & $2: 1$ & $\mathrm{H}_{3} \mathrm{BO}_{3}$ & 15 & $\mathrm{EtOH}$ & Reflux & 24 & 40 \\
\hline 12 & $2: 1$ & $\mathrm{H}_{3} \mathrm{BO}_{3}$ & 15 & n-Hexanol & Reflux & 24 & 62 \\
\hline 13 & $2: 1$ & $\mathrm{H}_{3} \mathrm{BO}_{3}$ & 15 & PEG-400 ${ }^{b}$ & Reflux & 24 & 30 \\
\hline 14 & $2: 1$ & $\mathrm{H}_{3} \mathrm{BO}_{3}$ & 15 & DMF & Reflux & 24 & 45 \\
\hline 15 & $2: 1$ & $\mathrm{H}_{3} \mathrm{BO}_{3}$ & 15 & Xylene & Reflux & 24 & Trace \\
\hline 14 & $2: 1$ & $\mathrm{H}_{3} \mathrm{BO}_{3}$ & 15 & Toluene & Reflux & 24 & 50 \\
\hline 17 & $2: 1$ & $\mathrm{H}_{3} \mathrm{BO}_{3}$ & 15 & - & 100 & 10 & 68 \\
\hline 18 & $2: 1$ & $\mathrm{H}_{3} \mathrm{BO}_{3}$ & 30 & - & 100 & 10 & 82 \\
\hline 19 & $2: 1$ & $\mathrm{H}_{3} \mathrm{BO}_{3}$ & 48 & - & 100 & 10 & 84 \\
\hline 20 & $2: 1$ & $\mathrm{H}_{3} \mathrm{BO}_{3}$ & 30 & - & 80 & 12 & 45 \\
\hline 21 & $2: 1$ & $\mathrm{H}_{3} \mathrm{BO}_{3}$ & 30 & - & 120 & 10 & 90 \\
\hline 22 & $2: 1$ & $\mathrm{H}_{3} \mathrm{BO}_{3}$ & 30 & - & 150 & 10 & 90 \\
\hline 23 & $2: 1$ & PTSA & 30 & - & 120 & 9 & 90 \\
\hline 24 & $1: 1$ & $\mathrm{H}_{3} \mathrm{BO}_{3}$ & 30 & - & 120 & 20 & 60 \\
\hline
\end{tabular}

Reaction conditions: 2-methyl-3-trifluoromethylanilin (2 mmol), 2-chloronicotinic acid (1 mmol)

The optimum reaction conditions are in italics

a 1,4-diazabicyclo[2.2.2]octane

b Polyethylene glycol

c The yields refer to the isolated product

equimolar ratios, a reduction in yield was observed (entry 24) and the optimum ratio of 2-methyl-3-trifluoromethylanilin (1) to 2-chloronicotinic acid (2) was 2:1 (entry 21).

Therefore, the optimum reaction conditions for the synthesis of flunixin were as follows: molar ratio of 2-methyl-3-trifluoromethylanilin (1) to 2-chloronicotinic acid (2) equal to $2: 1$ at $120{ }^{\circ} \mathrm{C}$ under solvent-free condition in the presence of $\mathrm{H}_{3} \mathrm{BO}_{3}(20 \mathrm{mg}, 30 \mathrm{~mol} \%)$ as catalyst (Table 1, entry 21). This procedure was also scaled up to $30 \mathrm{~g}$ of product and the yield of flunixin was maintained excellent however the reaction time was augmented about 45 min (Scheme 2).

The synthesized flunixin was characterized by FT-IR, ${ }^{1} \mathrm{HNMR},{ }^{13} \mathrm{CNMR}$ and GC/MS (see Additional file 1). A quantitative analysis was performed to determine the amount of residual boron in the synthesized flunixin. The result of ICP analysis shows a level of $2.23 \mathrm{ppm}$ $(2.23 \mathrm{mg} / \mathrm{L})$ of boron in the product. According to the World Health Organization, the health-based guideline for boron level in drinking water is $2.4 \mathrm{mg} / \mathrm{L}$.<smiles>Cc1c(N)cccc1C(F)(F)F</smiles>

Boric acid (30 mol \%)

Solvent free, $120^{\circ} \mathrm{C}, 10 \mathrm{~h} 45 \mathrm{~min}$

$44.45 \mathrm{~g}(0.254 \mathrm{~mol}) \quad 20 \mathrm{~g}(0.127 \mathrm{~mol})$

3a

$32 \mathrm{~g}, 85 \%$

Scheme 2 Scalability of the reaction to the multi-gram scale 
Table 2 Results of the synthesis of 2-arylaminonicotinic acids derivatives $3(b-I)$ under solvent-free conditions

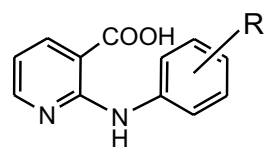

3(b-l)

\begin{tabular}{|c|c|c|c|c|c|}
\hline Entry & Anilines & Products & Time (min) & Yield $^{\mathrm{a}}(\%)$ & $\mathrm{Mp}\left({ }^{\circ} \mathrm{C}\right)$ \\
\hline 1 & 2-Chloroaniline & & 20 & 62 & $\begin{array}{l}213-215 \\
{[212-214][28]}\end{array}$ \\
\hline 2 & 2,6-Dichloroaniline & & 60 & 25 & $\begin{array}{l}264-267 \\
{[266-267][29]}\end{array}$ \\
\hline 3 & 3,4-Dichloroaniline & & 25 & 72 & $\begin{array}{l}258-260 \\
{[260][30]}\end{array}$ \\
\hline 4 & 2,3-Dichloroaniline & & 25 & 58 & $\begin{array}{l}256 \\
{[256-258][5]}\end{array}$ \\
\hline 5 & 2,4-Dimethylaniline & & 10 & 92 & $\begin{array}{l}225-227 \\
{[225][31]}\end{array}$ \\
\hline 6 & 3-Nitroaniline & & 30 & 90 & $\begin{array}{l}218-219 \\
{[216-218][32]}\end{array}$ \\
\hline 7 & 4-Nitroaniline & & 60 & 28 & $\begin{array}{l}274-275 \\
{[272-274][29]}\end{array}$ \\
\hline 8 & 1-Naphthylamine & & 30 & 85 & $\begin{array}{l}191-194 \\
{[193-194][33]}\end{array}$ \\
\hline 9 & 2-Aminophenol & & 25 & 88 & $\begin{array}{l}230-232 \\
{[230-232][34]}\end{array}$ \\
\hline
\end{tabular}




Entry 11 Anilines 10 Bethylamine

Reaction conditions: amines ( $2 \mathrm{mmol})$, nicotinic acid $(1 \mathrm{mmol})$, and $20 \mathrm{mg} \mathrm{H}_{3} \mathrm{BO}_{3}$ at $120^{\circ} \mathrm{C}$ under solvent-free condition

a The yields refer to the isolated product

Since we have been very successful in this solvent free approach with a very specific aromatic amine such as 2-methyl-3-trifluoromethylanilin, we decided to study the scope and limitation of the reaction using other aniline derivatives as nucleophiles. Reactions of aniline derivatives with 2-chloronicotinic acid gave good-to-excellent yields. This result was expected because the pyridine ring is activated toward nucleophilic attack by the formation of a pyridinium salt with the acid catalyst. Table 2 shows several 2-arylaminonicotinic acids derivatives synthesized under solvent-free condition in the presence of $20 \mathrm{mg}$ $\mathrm{H}_{3} \mathrm{BO}_{3}$ at $120^{\circ} \mathrm{C}$. As it can be seen, nucleophilic substitution takes place readily at the 2- and 4-positions of a ring particularly when substituted with an effective leaving group such as a halogen atom. In nucleophilic substitution, the intermediate is negatively charged.

The capacity of the ring to withstand the negative charge determines the stability of the intermediate and transition state which drives it and consequently determines the reaction rate. Nucleophilic attack at the 2-position yields a carbanion that is hybrid of structures. The hybrid structures of the anionic intermediate formed during the nucleophilic attack are especially stable, since the negative charge is located on the electronegative nitrogen atom which can better accommodate it (Scheme 3). For this reason the nucleophilic substitution occurs specially on the pyridine ring instead of the benzene ring and preferably at the 2 and 4 positions.

Various anilines were tolerated in this methodology and gave the product in good yield (Table 2, entries 1, $3,4,5,6,8,9$ ), but some anilines (entry 2 and 7) evince the influence of electron withdrawing group and steric hindrance on their reactivity by giving a low product yield. Remarkably, when primary amines other than anilines were selected for this transformation, no reaction was observed and they are not potent nucleophiles in this methodology; this could be attribute to the higher nucleophilicity of the acyclic primary amines poisoning<smiles>O=C(O)c1cccnc1Cl</smiles><smiles>N#CC1(Cl)N=CC=CC1=C([O-])O</smiles>

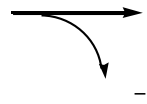

$\mathrm{Cl}$

Scheme 3 Nucleophilic substitution of a pyridine ring<smiles>N#Cc1ncccc1C(=O)O</smiles>

\section{Meisenheimer complex}


the catalyst as a result of competitive binding with the primary amine to the boric acid. The scope in substrates for nucleophilic substitution was also investigated using some pyridines derivatives such as 4-chloro pyridine, 3 -chloro pyridine and 2-chloro-5-nitro pyridine. However, when the reaction was run using these substrates, no product was observed even after $12 \mathrm{~h}$ (Table 3). The

Table 3 Scope in pyridine analogues for nucleophilic aromatic substitution

Entry Substrate $\quad$ Nucleophile $\quad$ Time (h)

Reaction conditions: aniline $(2 \mathrm{mmol})$, pyridine analogues $(1 \mathrm{mmol})$, and $20 \mathrm{mg}$ (0.3 mmol) $\mathrm{H}_{3} \mathrm{BO}_{3}$ at $120^{\circ} \mathrm{C}$ under solvent-free condition effect of other substituents on the pyridine ring show that the substitution reactions are more facile if an activating group is present on the ring. 2-chloronicotinic acid contains a strongly electron-withdrawing group $-\mathrm{COOH}$. This would be expected to better activate the halogen located ortho to it. This result clearly show the activating effect of the carboxylic acid group in $\mathrm{S}_{\mathrm{N}} \mathrm{Ar}$ of aromatic ring by forming resonance-stabilized intermediate known as Meisenheimer complex [27].

The results for synthesis of 2-arylaminonicotinic acids derivatives 3 are very satisfactory, affording the respective products in good yield in short reaction times.

Flunixin is not soluble in water, and as it is administered by intravenous or intramuscular injection consequently to increase its solubility in water, it is often formulated as the meglumine salt. Therefore the reaction of flunixin $(1 \mathrm{mmol})$ with meglumine $(1 \mathrm{mmol})$ was also examined under various reaction conditions and the results and the optimization of reaction conditions are summarized in Fig. 2.

As it can be seen, refluxing in ethanol gave the best results among all examined conditions. The as produced flunixin meglumine was characterized by FTIR, ${ }^{1} \mathrm{HNMR}$,

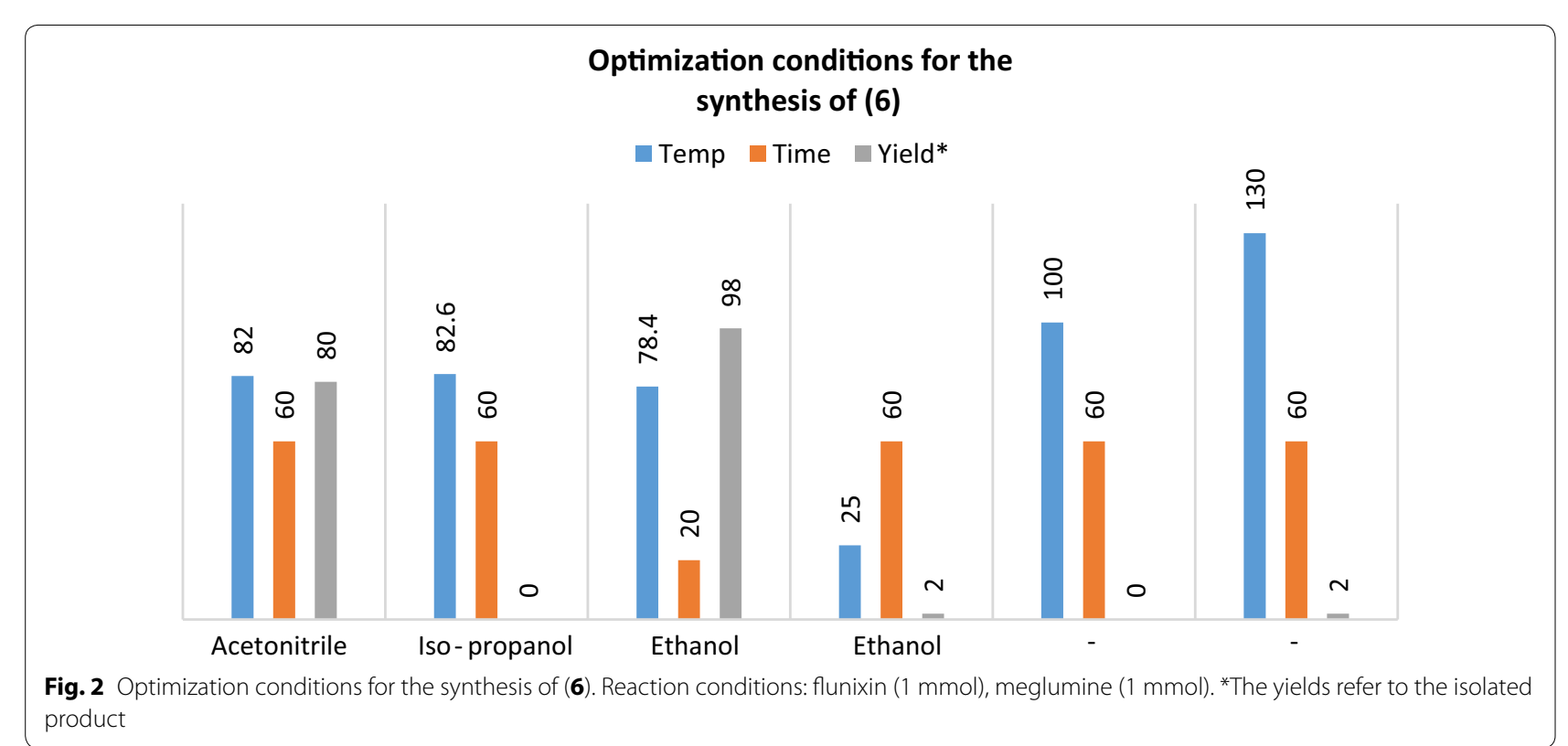

Fig. 2 Optimization conditions for the synthesis of (6). Reaction conditions: flunixin ( $1 \mathrm{mmol})$, meglumine ( $1 \mathrm{mmol})$. *The yields refer to the isolated
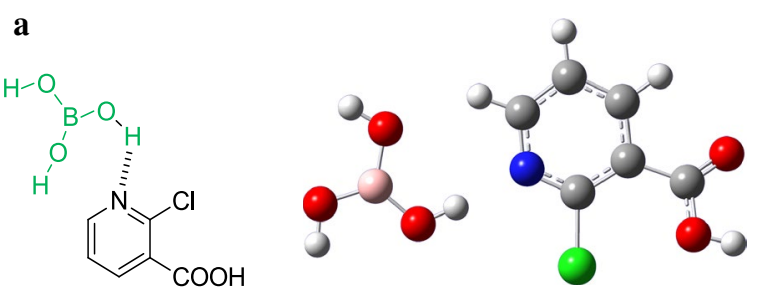

b
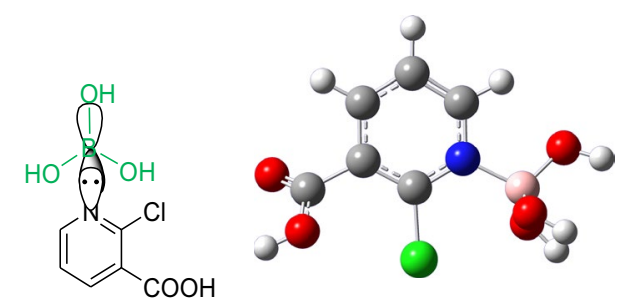

Fig. 3 Two possible pathway for catalytic activation of 2-chloronicotic acid with Boric acid. a HBD, b Boron-Nitrogen Lewis acid-base interaction 

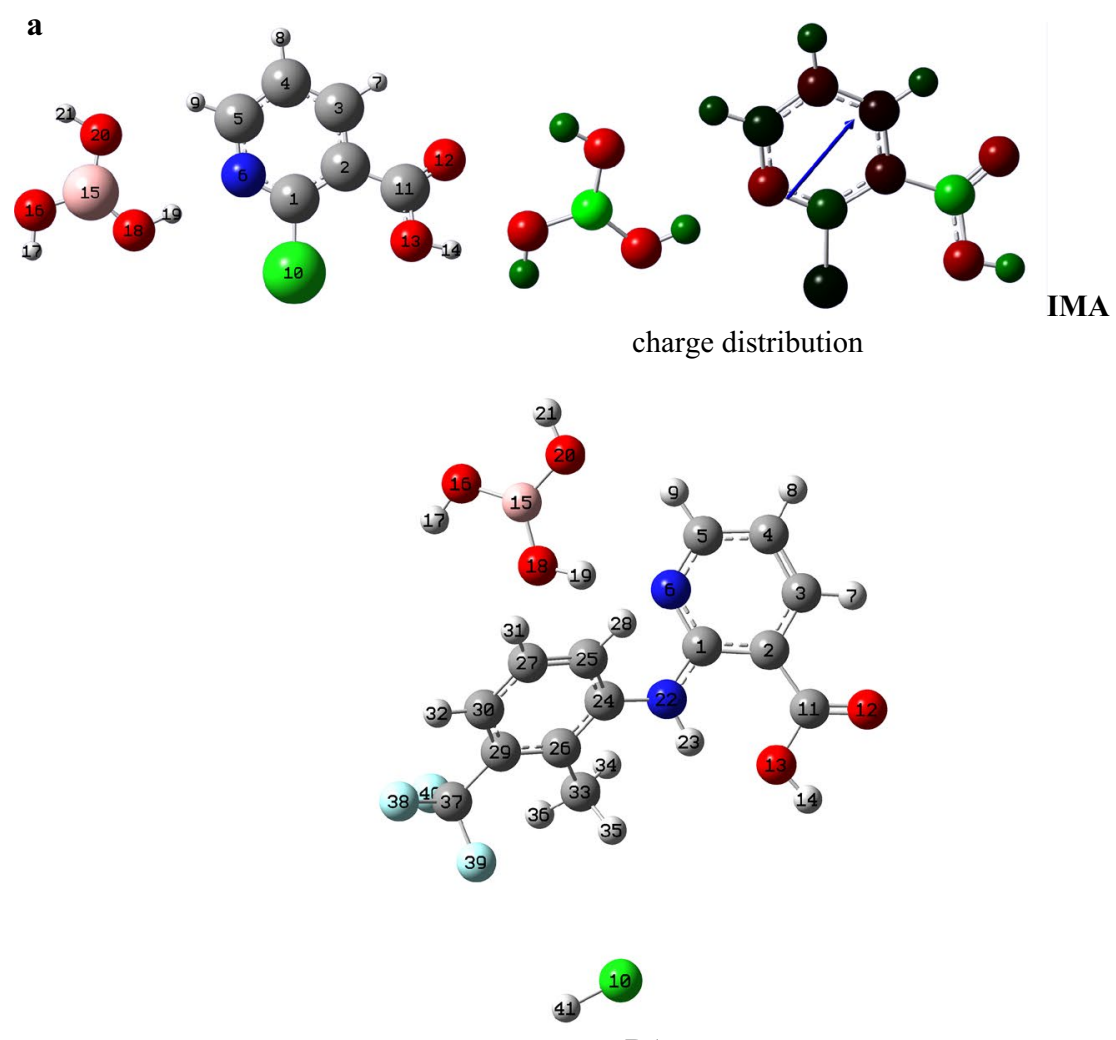
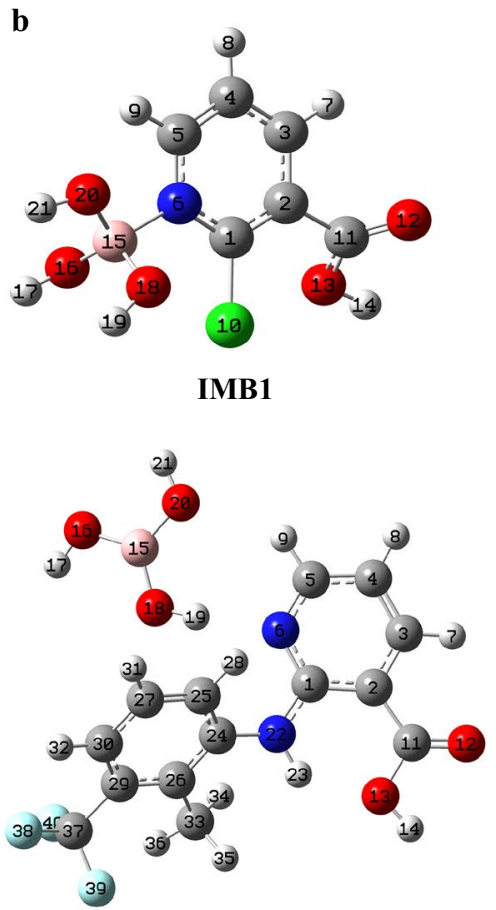

41. 10<smiles>COC(=O)C(C)C</smiles>

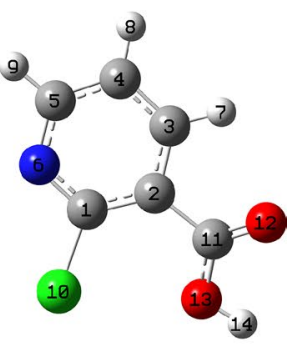

IMB 81

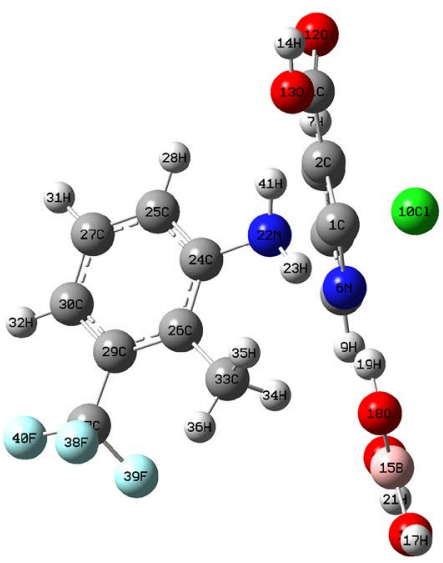

TS

Fig. 4 The optimized structures of nicotinic acid-boric acid, IMs, and product for pathway (a, b) by B3lyp/6-311G (d, p) singlet in the gas phase 
${ }^{13} \mathrm{CNMR}, \mathrm{GC} /$ Mass (available in Additional file 1) and high-performance liquid chromatographic (HPLC) method was used to determine the purity to flunixin meglumine (see Additional file 1). As can be seen from the HPLC chromatogram, the purity of the synthesized flunixin meglumine is higher than the standard.

\section{Theoretical study of mechanism}

The pathway for catalytic activation of 2-chloronicotic acid with Boric acid was investigated using theoretical gas-phase calculations [36]. The full geometry optimizations and property calculations were performed within the density functional theory (DFT) approach using the Becke's three-parameter B3LYP exchange-correlation functional [37] and the 6-311G** basis set [38, 39].

The two possible pathway for catalytic activation of 2-chloronicotic acid with Boric acid, i.e. hydrogen bonding and lone pair co-ordinate bond with the empty orbital on the boron are presented in Fig. 3. The optimized geometries of IMs, products $(\mathrm{P})$ and transition state (TS) and the numbering used in the analysis of the results are displayed in Fig. 4. The optimized bond lengths (in $\mathrm{nm}$ ) and stability energies $\mathrm{E}$ (a.u.) for IMs, TS and products are tabulated in Table 4.

The calculations overall indicate small affinity of boron for the nitrogen donor atom (IMB1) so that the optimized structure tend to form hydrogen bonds (HBDs) in (IMB 81) and give strong support to the suggested mechanism in which HBD formation between nitrogen in pyridine and $\mathrm{OH}$ of Boric acid is the preferred mode of activation. These results also showed that the internuclear distance C1-Cl10 increased from 1.75 in IMA to 2.04 in TS indicating the cleavage of this bonds while the inter-nuclear distance N22-C1 decreased from 1.91 in

Table 4 The optimized bond lengths (in $\mathbf{n m}$ ) and stability energies E (a.u.) computed at B3LYP/6-311G (d, p) level of theory for IMA, IMB, TS, PA, and PB (see Fig. 4 for atoms numbering)

\begin{tabular}{|c|c|c|c|c|c|}
\hline Bond length (nm) & IMA & IMB & TS & PA & PB \\
\hline (N6-H19) & 1.92 & 1.95 & & 1.92 & 1.92 \\
\hline (C1-Cl10) & 1.75 & 1.75 & 2.04 & & \\
\hline (C1-N22) & & & 1.91 & 1.37 & 1.37 \\
\hline E (stability energies in a.u.) & - 1149.199 a.u. & - 1149.193 a.u. & & - 1352.544 a.u. & - 1352.544 a.u. \\
\hline
\end{tabular}

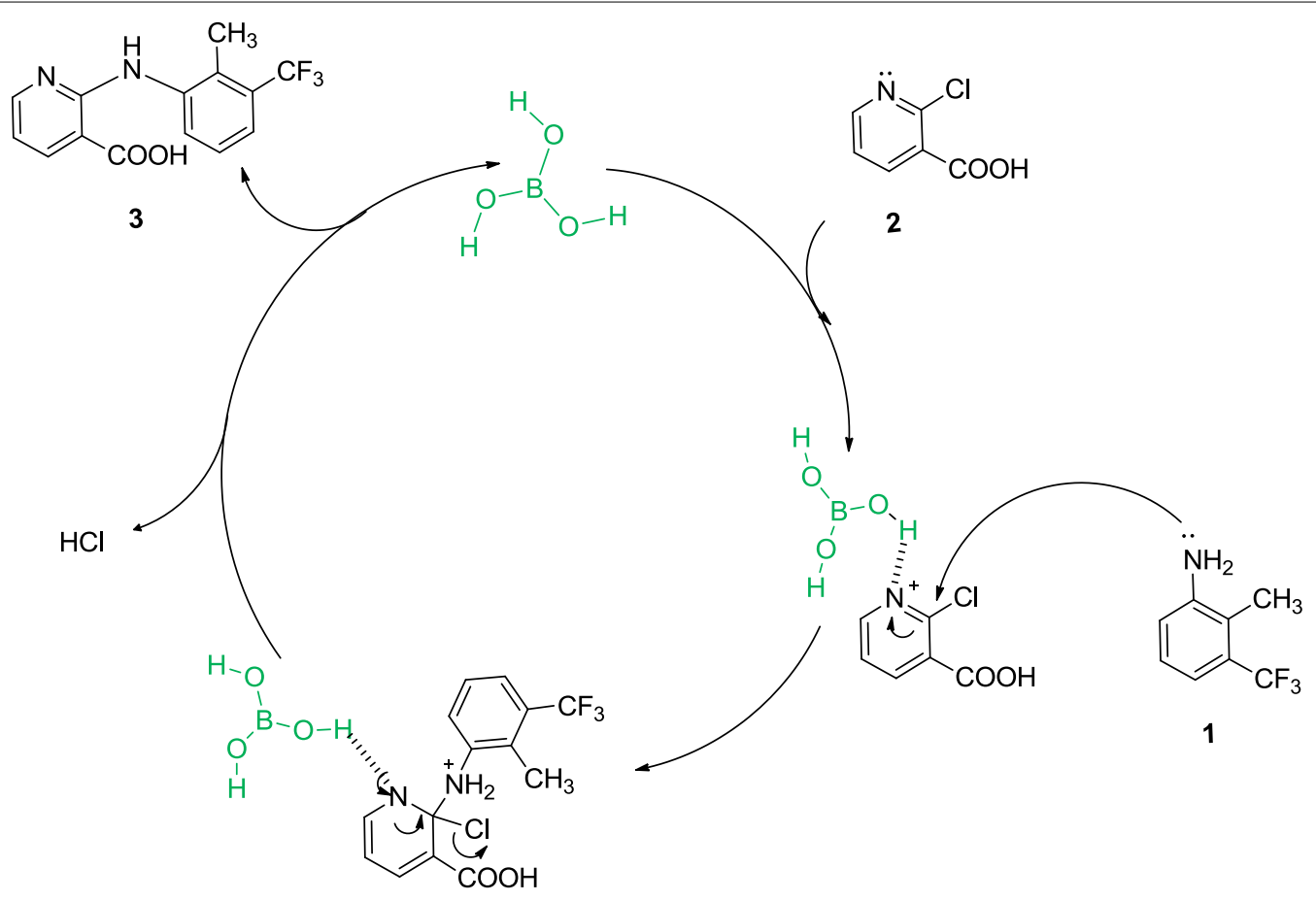

(I)

Scheme 4 Plausible mechanisms for the synthesis of flunixin 
TS to 1.37 (N21-C1) in PA. These observations provide evidence that the reaction proceeds through an addition elimination mechanism.

We also used Gaussian 03 [36] to observe the vibrations in the TS and saw that the negative frequency corresponded to the motion of $\mathrm{N} 22$ and Cl10. According to obtained results, the following proposed mechanism seems reasonable for the synthesis of flunixin catalyzed by boric acid (Scheme 4). The substitution reactions proceed via an addition-elimination mechanism. In this proposed mechanism the nucleophilic aromatic substitution reaction occurs via a two-step mechanism in which the first step is the addition

2-methyl-3-trifluoromethylanilin (1) to the pyridine ring of 2-chloronicotinic acid (2) which was activated through HBD between pyridine and Boric acid and so leading to the intermediate (I). In the second step elimination of the halide ion restores the aromaticity leading to the product (3a).

\section{Conclusion}

In summary, we have developed a simple, convenient and efficient method for the synthesis of flunixin using $\mathrm{H}_{3} \mathrm{BO}_{3}$ as catalyst under solvent-free conditions. This method are then extended for the synthesis of a series of 2-(arylamino)nicotinic acid derivatives. The present protocol has several advantages, particularly solvent- free conditions, high yields, ecofriendly operational, experimental simplicity along with mild conditions and the most important of them is development and optimization of flunixin meglumine synthesis in order to transfer to a larger scale for manufacture. Density function UB3LYP/6-311++g $(\mathrm{d}, \mathrm{p})$ calculations give strong support to the suggested mechanism in which HBD formation between nitrogen in pyridine and $\mathrm{OH}$ of Boric acid is the preferred mode of activation.

\section{Additional file}

Additional file 1. Supporting Information.

\section{Authors' contributions}

SJ have designed the study, participated in discussing the result, and revised the manuscript. MY carried the literature study, performed the assays, conducted the optimization as well as purification of compounds, and prepared the manuscript. ZD performed the NMR analyzes and assay validation studies. MGD is the second advisor and participate in final sequence alignment. All authors read and approved the final manuscript.

\section{Acknowledgements}

The authors gratefully acknowledge the support of the Research Council of the Iran University of Science and Technology, Tehran, IRAN. We also would like to express our very great appreciation to Mr. Khorsandi for his valuable time and help.

\section{Associated content}

Experimental procedure and product characterization data: $\mathrm{IR}^{1}{ }^{1} \mathrm{H} \mathrm{NMR},{ }^{13} \mathrm{C}$ NMR, GC/Mass and HPLC of compounds $\mathbf{3} \mathbf{a}$ and $\mathbf{6}$ are reported in Additional file.

\section{Competing interests}

The authors confirm that there are no known conflicts of interest associated with this publication and there has been no significant financial support for this work that could have influenced its outcome.

Ethics approval and consent to participate

Not applicable.

\section{Publisher's Note}

Springer Nature remains neutral with regard to jurisdictional claims in published maps and institutional affiliations.

Received: 9 October 2017 Accepted: 21 November 2017

Published online: 01 December 2017

\section{References}

1. Doran HJ (1993) United States Patent 07, 812, 183

2. Houdeshell JW, Hennessey PW (1977) A new nonsteroidal, anti-inflammatory analgesic for horses. J Equine Med Surg 1:57

3. Tobin T (1979) Pharmacology review: the nonsteroidal anti-inflammatory drugs. II. Equiproxen, meclofenamic acid, flunixin and others [used in horses]. J Equine Med Surg 3:298

4. Ciofalo VB, Latranyi MB, Patel JB, Taber RI (1977) Flunixin meglumine: a non-narcotic analgesic. J Pharmacol Exp Ther 200:501

5. McKillop A (1993) United States Patent 5, 248, 781

6. Jang D, Park J, Ko H, Jee J, Kim J, Kim S, Kim C, Jang DJ, Park JS, Ko HR, Jee JP, Kim JK, Kim ST, Kim CK (2005) Simultaneous determination of niflumic acid and its prodrug, talniflumate in human plasma by high performance liquid chromatography. Biomed Chromatogr 19:32

7. Cocco MT, Congiu C, Onnis V, Morelli M, Felipo V, Auli O (2004) Synthesis of new 2-arylamino-6-trifluoromethylpyridine-3-carboxylic acid derivatives and investigation of their analgesic activity. Bioorg Med Chem 12:4169

8. Yasunobu N, Toshikazu K (1990) Japanese Patent 02, 45, 451

9. Sherlock MH (1975) United States Patent 3, 891, 761

10. Towson JC, Coveney D (2013) United States Patent 8, 501, 788 B2

11. Gutsche CD, Johnson HE (1955) Ring enlargements. III. Ring enlargement of cyclohexanone with ethyl N-nitroso-N-benzylcarbamates carrying methyl and methoxyl substituents on the phenyl nucleus. J Am Chem Soc 77:109-112

12. Doran HJ, Coveney DJ (1995) European Patent 0, 619, 809

13. Sherlock MH, Long JF (1980) United States Patent 4, 205, 073

14. Hongbin Y, Na W (2006) Chinese Patent CN1803773 A

15. Sherlock MH (1974) United States Patent Office 3, 839, 344

16. Martin S, Wong YS (1980) United States Patent 4, 172, 095

17. Martin S, Wong YS (1980) United States Patent 4, 209, 464

18. Takeshi K, Toshikazu K, Hideki O (1988) Japanese Patent 86, 188, 576

19. Lamendola JF, Dhiru V, Robert T (1988) European Patent 295, 604

20. Jaouhari R, Quinn P, Jaouhari R, Quinn P (1994) Improved process for the preparation of 2 methyl-3-trifluoromethylaniline: a versatile intermediate for flunixin synthesis. Heterocycles 38:2243

21. Tanaka K (2009) Solvent-free organic synthesis, 2nd edn. Wiley-VCH, Weinheim

22. Nguyen TB, Jonathan S, Minh QT, Ludmila E, Ali M (2012) Boric acid: a highly efficient catalyst for transamidation of carboxamides with amines. Org Lett 14:3202

23. Ravi KM, Kondaiah G, Naveenkumar K, Raju V, Purandhar K, Apurba B, Rakeshwar B (2007) Boric acid catalyzed amidation in the synthesis of active pharmaceutical ingredients. Org Process Res Dev 11:1065

24. Thomas S, Hansen A, Jerrik M, Anders R (2011) Synergy of boric acid and added salts in the catalytic dehydration of hexoses to 5-hydroxymethylfurfural in water. Green Chem 13:109 
25. Tang PW (2005) Boric acid catalyzed amide formation from carboxylic acids and amines: N-benzyl-4-phenylbutyramide. Org Synth 81:262

26. Shelke KF, Sapkal SB, Kakade GK, Shinde PV, Shingate BB, Shingare MS (2009) Boric acid as an efficient catalyst for the synthesis of 1, 1-diacetate under solvent-free condition. Chin Chem Lett 20:1453

27. Meisenheimer J (1902) Ueber reactionen aromatischer nitrokörper. Eur J Org Chem 323(2):205

28. Li ZH, Xia ZN, Chen G (2011) Catalyst-free amination of 2-chloronicotinic acid in water under microwave irradiation. J Chem Res 35:709

29. Stampa A (1973) France Patent 2236862-A1

30. Mefetah H, Brouant P, Galy A, Galy J, Barbe J (1995) Potential anticancer benzo-naphthyridones with fused rings: a theoretical model for predicting orientation in the cyclization of intermediates. Med Chem Res 5:522

31. Montginoul B, Giral T (1980) Synthese de nouvelles $1 H$, $3 H$ pyrido[2,3- $d$ ] pyrimidinediones-2,4. J Heterocycl Chem 17:235

32. Kolodziejczyk A, Arendt A (1975) Synthesis of a tumor-growth inhibitor-dihydrochloride of 1-nitro-9-/dimethylamino-propylamino/acridine/C-283/tritium labelled in the acridine ring and 14C-labelled in the side chain. J Label Compd 11:385

33. Li Z, Xiao Sh, Liang R, Xia Z (2012) Synthesis of 2-(arylamino) nicotinic acids in high-temperature water. Res Chem Intermed 38:1691

34. Sherlock M, Kaminski J, Tom C, Lee F (1988) Antiallergy agents. 1. Substituted 1, 8-naphthyridin-2 (1H)-ones as inhibitors of SRS-A release. J Med Chem 31:2108
35. Scherrer RA, Beatty HR (1980) Preparation of o-substituted benzoic acids by the copper(II)-catalyzed reaction of diphenyliodonium-2-carboxylate with anilines and other nucleophiles. J Org Chem 45:2127

36. Gaussian 03, Revision C 02, Frisch MJ, Trucks GW, Schlegel HB, Scuseria GE, Robb MA, Cheeseman JR, Zakrzewski VG, Montgomery JA, Stratmann RE, Burant JC, Dapprich S, Millam JM, Daniels AD, Kudin KN, Strain MC, Farkas O, Tomasi J, Barone V, Cossi M, Cammi R, Mennucci B, Pomelli C, Adamo C, Clifford S, Ochterski J, Petersson GA, Ayala PY, Cui Q, Morokuma K, Malick DK, Rabuck AD, Raghavachari K, Foresman JB, Cioslowski J, Ortiz JV, Baboul AG, Stefanov BB, Liu G, Liashenko A, Piskorz P, Komaromi I, Gomperts R, Martin RL, Fox DJ, Keith T, Al-Laham MA, Peng CY, Nanayakkara A, Challacombe M, Gill PMW, Johnson B, Chen W, Wong MW, Andres J, Gonzalez C, Head-Gordon M, Replogle ES, Pople JA (1998) Gaussian 98, Revision A.9. Gaussian Inc, Pittsburgh

37. Becke AD (1988) Density-functional exchange-energy approximation with correct asymptotic behavior. Phys Rev A 38:3098

38. Lee CT, Yang WT, Parr RG (1988) Development of the Colle-Salvetti correlation-energy formula into a functional of the electron density. Phys Rev B 37:785

39. Frisch M, Head-Gordon M, Pople J (1990) Semi-direct algorithms for the MP2 energy and gradient. Chem Phys Lett 166:281

\section{Submit your manuscript to a SpringerOpen ${ }^{\circ}$ journal and benefit from:}

- Convenient online submission

$\checkmark$ Rigorous peer review

- Open access: articles freely available online

- High visibility within the field

- Retaining the copyright to your article

Submit your next manuscript at $\mathbf{s p r i n g e r o p e n . c o m ~}$ 